\title{
Some Issues on the Funding of the Scientific Publication in Open Access
}

\author{
Maria José Sá \\ CIPES-Centre for Research in Higher Education Policies, \\ Matosinhos, Portugal
}

\section{Sandro Serpa}

\author{
University of the Azores, Faculty of Social and Human Sciences, Department of Sociology; \\ Interdisciplinary Centre of Social Sciences - CICS.UAc/CICS.NOVA.UAc; \\ Interdisciplinary Centre for Childhood and Adolescence - NICA - UAc, Ponta Delgada, Portugal
}

DOI: https://doi.org/10.36941/ajis-2020-0063

\section{Abstract}

The academic/scientific publication in Open Access is already a current practice with several advantages, and the trend is that it will continue to be adopted worldwide by academics and researchers to disseminate the results of their work among the scientific community and the public at large. At a time when Open Access is not only unavoidable but tends to become generalised as a form of scientific publication, this paper seeks to put forth, discuss and analyse some emerging issues, which are directly related to the financing of the publication of scientific research in Open Access, and which are directly linked to the consequences for academic freedom and the impact of the dissemination of the scientific publication, as current questions that shape the scientific publication that we will have and wish. The results of this analysis allow concluding that, for this new way of publishing science to grow in a sustained way, it is necessary to ensure, among other aspects, the existence of independent scientific advisory boards; freedom of publication within certain boundaries; a sustainability strategy to plan for the operation of the platform; transparency in public scrutiny; and respect for the law.

Keywords: open access, scientific publication, article processing charges, publication funders, funding sources, scholarly publishing

\section{Introduction}

Science, in general, has two dimensions: the process and the product. The scientific process consists of research in which, in a rigorous way and through controlled procedures, researchers seek to know more about the real through a definition of the object of study, the application of theories to account for the real, and methods of gathering information, in an attempt to answer research questions (Ferreira \& Serpa, 2017). The product, for the purposes of this work, consists of the dissemination of the research process results and is materialised in articles, books and communications, among other scientific outlets.

The article, as a scientific publication, is increasingly valued (Kortabarria, 2020; Balaji \& Dhanamjaya, 2019), almost "as if it were at the end of a kind of knowledge production chain" (Botelho, Brasil Jr. \& Hoelz, 2019, p. 722). 
The scientific publication is critical in the scientific, but also at the professional and social fields (Hughes, Stone, Aravopoulou, Tiu Wright, \& Machtynger, 2018). According to Sandu (2012), the central purpose of the scientific publication is the dissemination of the results and conclusions attained by the research conducted by its authors. This dissemination is carried out, inter alia, through the publication of articles in scientific journals, and it is "[...] considered as part of marketing science and personal branding of the author and not the mere fulfillment of contractual or ethical obligations to disseminate the research results" (Sandu, 2012, p. 8).

In the current higher education context, there is enormous pressure on academics to publish, both for professional reasons and for the institutional position of their institution (Kortabarria, 2020; Aliukonis, Poškutè, \& Gefenas, 2020; Abbott, 2018; van Dijk \& van Zelst, 2020). According to Kortabarria (2020), with the pressure materialised by the expression "publish-or-perish" (used for the first time in a non-academic context by Harold Jefferson Coolidge, in his 1932 book Life and Letters, by Archibald Cary Coolidge, but which eventually became popular in the academic environment (Rawat \& Meena, 2014), academics have no option but to "[...] publish in a closed online environment - such as their institutional repository [...] - or in a universal, well-established and very reputable, but increasingly onerous or even, for some, prohibitive journal" (Kortabarria, 2020, p. 224).

This pressure to publish can raise ethical questions in several dimensions of scientific creation and publication. Among other authors and studies, Aliukonis et al. (2020) warn of the existence of unethical authorship, namely, honorary and ghost authorship, and Tennant et al. (2019) mention issues related to copyright transfer.

This takes place in a context in which Open Access (OA) has emerged and is consolidated in the scientific publication, in its advantages but also its limitations (Gamsby, 2019; Tennant et al., 2019; Lange, 2016). One of these limitations is "the money-making by predatory publishers" (Sorooshian, 2019, p. 1), which are increasing. The author is quite critical, stating that "a few unprofessional publishers [...] abuse their authors' trust and make money" (Sorooshian, 2019, p. 1), without worrying about the accuracy, either in the content or even in the form of what they publish. Sorooshian (2019) continues its criticism of these publishers, namely regarding the financial costs of publishing in OA, drawing attention to "Unrealistic publication and/or submission fees, demanding payments for (unnecessary and/or unlikely) language proofreading and/or manuscript formatting, and additional costs for a fast track review are among the tactics that unprofessional journals may take to make money" (p. 1).

In this context, the scientific publication system tends to move, to a large extent, from a payper-read policy, in the form of payment per article/reading or a usually institutional subscription, to Article Publishing Charges (APCs), in which the author, or someone on his/her behalf, pays a publication charge to enable the publication of the article (Kortabarria, 2020; Tennant et al., 2019). The financing of the publication in OA is still insufficient (Click \& Borchardt, 2019). Yet, the authors maintain that "[...] institutions with OA funds may need to identify opportunities to increase support for high-impact publications, as well as consider the financial stability of these funds" (p. 22).

In summary, at a time when OA is not only inevitable but tends to become widespread as a form of scientific publication, this document is an occasion to discuss some issues that arise and that are directly linked to the consequences for academic freedom and the impact of the dissemination of the scientific publication as current questions that shape the scientific publication that will be and desired for the future. These are current issues that shape the present and future scientific publication, and pose profound challenges.

\section{The Open Access Scientific Publication}

In a thorough literature overview, van Dijk and van Zelst (2020) maintain that the publication system should serve five functions. These functions are depicted in Table 1. 
Table 1. Functions of the publication system

\begin{tabular}{|l|l|}
\hline Registration & $\begin{array}{l}\text { Regards to how a study has taken place and enables claiming precedence of a scholarly } \\
\text { contribution. In the current journal-based publishing system, this occurs when a paper is } \\
\text { published. }\end{array}$ \\
\hline Certification & $\begin{array}{l}\text { Concerns the process through which the contribution is validated. This typically occurs via } \\
\text { peer review and editorial guidance. }\end{array}$ \\
\hline Awareness & Entails the ways in which scientific contributions are disseminated among stakeholders. \\
\hline Archiving & $\begin{array}{l}\text { A publication system should keep a record over time of all scholarly contributions. } \\
\text { Journals, as well as repositories, do this online, whereas libraries usually keep printed } \\
\text { copies. }\end{array}$ \\
\hline Rewarding & $\begin{array}{l}\text { The system should generate metrics that can be used for evaluating and rewarding } \\
\text { researchers. Such metrics are predominantly journal-based (e.g., impact factor), but there is } \\
\text { an increase in metrics at the individual researcher level (e.g., citations, h-index), as well as } \\
\text { so-called altmetrics, which are placed at the article level (e.g., the amount of reads or the } \\
\text { amount of mentions an article receives in social media). }\end{array}$ \\
\hline
\end{tabular}

Source: Based on van Dijk, \& van Zelst, 2020, p. 3.

The possibility of publishing in the digital setting and format (Million \& Hudson Vitale, 2019) - with the same print standards such as an ISSN (International Standard Serials Number), and with enriching additions such as the possibility of indicating a DOI (Digital Object Identifier) for each article, thus facilitating research - has become the mainstream, and today virtually all scientific journals not only have a digital version (with the same quality as the printed version), but, for economic and environmental reasons, but also the practicability of publication and research, journals' printed versions tend to be abandoned. According to Kortabarria (2020), "a scientific journal was perceived as needed, because the academia increasingly needed the fast turnaround that only an on-line platform could provide" (p. 223).

From the previous digital with the use of the Internet, as well as policy options, Open Access emerged, which begins to be mainstream publishing instead of subscription-based publishing (Kortabarria, 2020; deBronkart, 2019). This increasingly used scientific outlet, with variations (Kortabarria, 2020), consists essentially of

[...] free availability on the public internet, permitting any users to read, download, copy, distribute, print, search, or link to the full texts of these articles, crawl them for indexing, pass them as data to software, or use them for any other lawful purpose, without financial, legal, or technical barriers other (Budapest Open Access Initiative, cit. in Kortabarria, 2020, p. 225).

However, publishing in $\mathrm{OA}$ is not necessarily equivalent to the "pay-to-publish" model, varying according to the scientific area. In the humanities and social sciences, the journals are mostly small and very few charge APCs, with difficulties in knowing the fair value. Kortabarria (2020) offers an objective synthesis of the services/products that APCs normally include, in addition to ensuring that access to the full version of articles is permanent, global and immediate:

- Editorial work: peer review, administrative support, commissioning content, journal development.

- Technical infrastructure and innovation: development, maintenance and operation of online journal system and websites.

- Production of articles: formatting and mark-up of articles and inclusion in indexing services

- Marketing of journal and content: making sure readers and authors know about the work published in the title.

- Customer service: responding to authors and readers (Kortabarria, 2020, p. 233).

This OA publication model, which, if correctly used, will not question the quality of what is published (Tennant et al., 2019), functions, in most cases, according to the paid-for model 
(Kortabarria, 2020). However, the APC is too often hyper-inflated vis-à-vis the service provided by the publishers, with profound variations according to each specific journal but also the scientific area in question (Tennant et al., 2019; Copiello, 2020; Ross-Hellauer, Schmidt, \& Kramer, 2018). Table 2 offers an example of the six key stages throughout the lifecycle of an OA publication (Taylor, 2019).

Table 2. Six key stages throughout the lifecycle of an open access publication

\begin{tabular}{|l|l|}
\hline Commissioning & $\begin{array}{l}\text { A well thought out commissioning plan for books and journals is key if publishing } \\
\text { activities are going to be strategic and targeted, rather than reactive. }\end{array}$ \\
\hline Review & $\begin{array}{l}\text { In a proactively review, the journals operate a double blind peer review system as } \\
\text { standard for OA journals, and the review process for monographs is just as rigorous, if } \\
\text { slightly different. Transparency is particularly important for OA publications. }\end{array}$ \\
\hline Production & $\begin{array}{l}\text { Whilst the overhaul of the production process addresses issues of capacity and } \\
\text { workflow, it is also being made in response to current developments across the wider } \\
\text { higher education and research environment. }\end{array}$ \\
\hline Discoverability & $\begin{array}{l}\text { To ensure the full benefits of OA publications, it must be made easy to find and use. Yet, } \\
\text { simply placing research outputs in an institutional repository is not enough. There are } \\
\text { potential channels for increasing research discoverability, such as SCOPUS, JSTOR and } \\
\text { DOAJ, among others. }\end{array}$ \\
\hline Marketing & $\begin{array}{l}\text { Following on from discoverability, once you have made your content available and } \\
\text { accessible to a wide audience, how do you go about marketing it? With OA content, } \\
\text { authors want to encourage readership of it, but they can utilise all of the content and } \\
\text { market to any appropriate audience, as there are no restrictions on access. }\end{array}$ \\
\hline Analytics & $\begin{array}{l}\text { Finding useful analytics to monitor can aid forward planning and enable more strategic } \\
\text { decisions to be made around future activities and campaigns. Alongside altmetrics } \\
\text { analytics, currently, the only way the Press can monitor citations is manually via Google } \\
\text { Scholar, which means that the data made available is limited, time consuming to collate } \\
\text { and not fully comprehensive. }\end{array}$ \\
\hline
\end{tabular}

Source: Adapted from Taylor, 2019.

This option, which allows, with low costs and through OA, to publish on the digital milieu with the possibility of charging APCs, has raised several challenges, such as publications and publishers referred to by several researchers as low-quality or "predatory publications" (Eykens, Guns, Rahman, \& Engels, 2019). However, "Predatory publishing does not refer to a homogenous category of practices" (Tennant et al., 2019, p. 8). According to the authors, the real issue is the fact that a business model has been imported into the scientific publishing arena, and it is being used by numerous publishers in an unethical and/or unprofessional way. The solution would be to make use of greater transparency in peer-review and publication processes (Tennant et al., 2019). The authors underline the significance of making a clear distinction between "[...] exploitative publishers and journals - whether OA or not - and legitimate OA initiatives with varying standards in digital publishing" (Tennant et al., 2019, p. 9).

One of the criteria for measuring the quality of the scientific publication may be the indexing of the journal to several disciplinary databases. Some of these are the Web of Science (WoS), Elsevier's Scopus Bibliometric Data Journal Impact Factor, CiteScore, Scimago Journal Rank, Source Normalized Impact per Paper metrics for journals and h-index, iı-index, and s-index (Balaji \& Dhanamjaya, 2019). Some of them, notably WoS and Scopus, use very strict selection criteria, since "Both are commercial enterprises, whose standards and assessment criteria are mostly controlled by panels of gatekeepers in North America and Western Europe" (Tennant et al., 2019, p. 15). Furthermore, the assessment or measurement of the impact and quality of an article and a journal is not direct or guaranteed through metrics, whether traditional bibliometric indicators or social mediabased altmetrics (Tennant et al., 2019; Lemke, Mehrazar, Mazarakis, \& Peters, 2019; Balaji \& Dhanamjaya, 2019). 
According to Cantrell and Swanson (2020), funding strategies should be periodically reassessed and diversified as more researchers and publications from various disciplines choose to publish in $\mathrm{OA}$. As the trend is that OA will become increasingly used by academia, increased attention will be needed in understanding how the various funding models support OA publishing in all disciplinary fields and types of research outputs (Cantrell \& Swanson, 2020).

\section{The Funding of the Scientific Publication}

\subsection{The arriving on the scene}

Kortabarria (2020) sustains that publishers of scientific outputs follow two key logics: (i) publishers almost always charge authors APCs for publishing in OA; and (ii) publishing in subscription-based journals can free authors from any costs, inasmuch that the readers and/or institutions cover (with the payment of their subscription) the costs of producing the contents. These costs include "commissioning, copyediting and proofreading, production, dissemination and promotion" (Kortabarria, 2020, p. 228) of the authors' work, "including online hosting and indexing" (p. 228). The author also advocates that the "predatory journals could be fought against - simply by leaving the financial profit factor out of the equation" (Kortabarria, 2020, p. 235).

Academic publishing also functions according to a market-based logic, and profit is, by definition, the key element (Kortabarria, 2020). However, there are specificities in this scientific publishing "industry", in which the largest share of funding hardly comes from the journal. As the author stresses,

The way to make money from a scientific article looks very similar, except that scientific publishers manage to duck most of the actual costs. Scientists create work under their own direction - funded largely by governments - and give it to publishers for free; the publisher pays scientific editors who judge whether the work is worth publishing and check its grammar, but the bulk of the editorial burden - checking the scientific validity and evaluating the experiments, a process known as peer review - is done by working scientists on a volunteer basis (Buranyi, 2017, cit. in Kortabarria, 2020, p. 230).

A form of free-of-charge publication is the preprint. It consists of a version of a scientific article that is made available online even before its potential publication (often even before the formal peer review-process (Tennant et al., 2019). Balaji and Dhanamjaya (2019) argue that "Open science through preprints promote transparency and secure provenance, time, and integrity of scientific data in an open and distributed infrastructure documenting every step of the research process and data for public" (p. 19). Balaji and Dhanamjaya (2019) stress that one of the main developments in academic and scientific communication since the 1990s is the growth of preprints repositories as a new model of scientific publication. This development and increase in the scientific publication through preprints mirrors the transition that is taking place in the way of making scientific communication and dissemination, with the introduction and widespread use of alternative metrics, namely the attention of the social media, as well as metrics at the author's and the article's level (Balaji \& Dhanamjaya, 2019). The authors alert, however, that preprints' sustainability heavily relies on support to and investment in open knowledge by scholarly communities and funding agencies, as well as on alternative metrics development and open infrastructures in scientific publishing (Balaji \& Dhanamjaya, 2019).

\subsection{Challenges}

The OA scholarly publication benefits from the establishment of several grant funding both public and private mandates/agencies to finance the publication, almost always in the OA model (Lange, 2016; Ross-Hellauer et al., 2018; Mathies, Kivistö, \& Birnbaum, 2019; Besir Demir, 2018; Gamsby, 2019). Some examples of these supports are Plan $S$ (2020) and Horizon 2020, among many others. In this 
regard, Ross-Hellauer et al. (2018) state that,

In the age of open access (OA), research funding organizations have taken a more active interest in academic publishing. To increase access to research results stemming from their funding, they are increasingly directly funding publishing (via article processing charges), supporting infrastructures, and introducing policies to require their researchers to publish OA. A step-change in this engagement is the recent phenomenon of OA publishing platforms commissioned by funding organizations. Examples include those of the Wellcome Trust and the Gates Foundation, as well as recently announced initiatives from public funders like the European Commission (EC) and the Irish Health Research Board (HRB) (p. 1).

According to Ross-Hellauer et al. (2018), the relationship between research-funding entities and the scientific publication seems to have moved into a new phase of involvement in times of digital publication and OA. The freedom researchers have to select where to publish their research results is synonymous with fundamental academic freedom. For this reason,

[...] many funders support the costs of APCs, either by making them eligible grant costs or by making available earmarked funds. This constitutes a considerable new financial burden for funders, who obviously have an interest in keeping costs down. However, controlling costs can be in conflict with the aim of increasing uptake of OA (Ross-Hellauer et al., 2018, p. 3).

There are several differences between these APC funds and crowdfunded models such as Knowledge Unlatched, $\mathrm{SCOAP}_{3}$ and Unglue.it (for an excellent discussion of Plan S, see Frantsvåg \& Strømme, 2019; Gamsby, 2019). Instead of paying individual APCs for OA publications, libraries pay for institutional memberships with specific publishers that include APC discounts, as well as initiatives with "wide potential global impact", such as arXiv and the Open Textbook Network (University of Arizona University Libraries, 2019, cit. in Click \& Borchardt, 2019). Ross-Hellauer et al. (2018) provide the following example:

The platform [EC's Open Research Europe] is intended for Horizon 2020 beneficiaries to publish "scientific articles" in all major fields of scholarship, including Social Sciences and Humanities (SSH). The publication model specified diverged somewhat from the other funder platforms established until that time, in that it should offer two options: (a) a standard option in which manuscripts are peer reviewed before publication and (b) a model in which manuscripts are uploaded to a preprint server in advance of peer review. Peer review would in both cases be "open peer review," although there were no exact specifications as to what aspects (Ross-Hellauer, 2017) of open peer review should be included, nor whether the publication of reviewer names or reports should happen after publication or in real time. Both preprints and peer-reviewed articles should be licensed either Creative Commons CCo or CC-BY "or equivalent," and text- and data-mining should be offered "in accordance with existing practices as they evolve over time (Ross-Hellauer et al., 2018, p. 8).

This recent movement of research funding by several entities, namely through the provision of platforms for publication in OA with the brand of the funding entity, reveals that they wish to take on a new and active role in scientific communication and dissemination. Building on Ross-Hellauer et al. (2018), these entities control and evaluate the publication process in two fundamental ways:

- A publication platform funded by a given entity allows a better overview of the publications produced within the framework of research it funds and to more easily monitor the use and acceptance of the platform.

- A second and more direct form of control is that funders require that the research they fund is disseminated on their specific publication platform, either exclusively or in addition to the publication in other outlets.

However, these new developments may bring about a shift in the balance between the mandate of the publication in OA, insofar that donors provide the platforms for such dissemination but require authors to use them. Thus, funding agencies may accelerate scientific publication in OA through their own market interventions. However, this should be done not only by acquiring what is offered by the market - in this case, the market for academic publications - but, more than that, by taking on an active role in encouraging the development of models. In this way, these entities will be 
contributing to an active and differentiated way to the promotion of the desired innovation in the arena of scientific communication and dissemination (Ross-Hellauer et al., 2018).

The issues related to the funding of scientific publication platforms cause constraints and concerns about unintended or negative consequences of this type of scientific dissemination. Table 3 highlights some of these areas for concern.

Table 3. Concerns and recommendations about OA funding

\begin{tabular}{|c|c|}
\hline Conflict of Interest & $\begin{array}{l}\text { Potential control of the funder over the publication process brings to light the } \\
\text { possible conflict of interest that may be perceived when funders provide the } \\
\text { publishing platform for the research, they finance. }\end{array}$ \\
\hline Scale & $\begin{array}{l}\text { This approach may not be suitable for smaller funders, who may believe they do } \\
\text { not have the name-brand recognition to create and sustain such a platform or be } \\
\text { concerned about the costs of operation. }\end{array}$ \\
\hline Lock-in & $\begin{array}{l}\text { Using private-sector infrastructure to support such platforms also causes an all-too } \\
\text { familiar concern, however: How to avoid vendor lock-in? }\end{array}$ \\
\hline $\begin{array}{l}\text { Need to support } \\
\text { wider OA initiatives }\end{array}$ & $\begin{array}{l}\text { To support true innovation, funders should also continue to support wider } \\
\text { initiatives in scholarly communication and seek to integrate them with their } \\
\text { existing infrastructure on the basis of interoperability. }\end{array}$ \\
\hline Branding issues & $\begin{array}{l}\text { While the focus of publishing should be the on the quality of the research itself, a } \\
\text { venue also takes on its own value. Dangers: the funder OA platforms may be seen } \\
\text { as second-class venues for "the rest" of research; especially in the case of highly } \\
\text { selective funders, the funder name becomes its own perceived badge of quality. }\end{array}$ \\
\hline $\begin{array}{l}\text { Listen to } \\
\text { stakeholders and } \\
\text { respect diversity }\end{array}$ & $\begin{array}{l}\text { Uptake from researchers requires that platforms reflect researcher-needs and } \\
\text { expectations in the present, and evolve in response to emergent user needs and } \\
\text { attitudes in the future. Such platforms should reflect genuine difference in } \\
\text { attitudes among different stakeholder groups, and the need for situated openness. }\end{array}$ \\
\hline $\begin{array}{l}\text { Maximise } \\
\text { operational } \\
\text { transparency and } \\
\text { accountability }\end{array}$ & $\begin{array}{l}\text { Given the potential for the emergence of conflicts of interest in a funder directly } \\
\text { supporting a platform for the dissemination of its research, it is imperative to build } \\
\text { trust via openness and transparency of processes, supported by the openness of } \\
\text { peer review and editorial processes that such platforms have thus far employed. } \\
\text { Furthermore, higher structures of governance should also be maximally } \\
\text { transparent, trustworthy and accountable to it. To ensure long-term commitment } \\
\text { and trust, independence of higher structures of governance is also critical. }\end{array}$ \\
\hline $\begin{array}{l}\text { Embrace } \\
\text { interoperability }\end{array}$ & $\begin{array}{l}\text { It should be emphasised that, for maximum re-usability, reproducibility, and } \\
\text { transparency, such platforms should publish all research objects (including data, } \\
\text { software and research protocols), with open standardized metadata to establish the } \\
\text { links between them, and apply open licenses to maximize re-use by humans and } \\
\text { machines. }\end{array}$ \\
\hline Prefer open source & $\begin{array}{l}\text { Whether from the private or public sector, it is crucial that OA funder platforms } \\
\text { avoid becoming bound to specific organisations for technologies or workflows such } \\
\text { that the cost of transferring to another platform/organisation becomes prohibitive. }\end{array}$ \\
\hline Think bigger & $\begin{array}{l}\text { The platforms commissioned thus far reflect the state-of-the-art in established } \\
\text { standards and technologies for Open Science publishing platforms, using such } \\
\text { platforms, especially once established, as venues for experimentation with } \\
\text { genuinely ground-breaking models and technologies. }\end{array}$ \\
\hline
\end{tabular}

Source: Based on Ross-Hellauer et al., 2018.

Click and Borchardt (2019) identified fund guidelines and evaluative criteria for funding scientific publication in OA according to three main variables:

- Author Eligibility. These policies often stated that the amount of funding was proportional to the number of authors of a given publication. On the other hand, this funding would be granted proportionally to the percentage of authors associated with the institution. 
Moreover, these funds could only be used when the author(s) exhausted other sources of funding.

- Publication Eligibility. All funds covered articles in journals, although the criteria for their inclusion were different. In addition to this publication format, funding included other publications, such as monographs, book chapters, and conference proceedings, among others.

- Funding. The vast majority of the funds identified by the authors came from the libraries of the funding institutions.

The most frequently mentioned criteria was the inclusion in the Directory of Open Access Journals (DOAJ), followed by membership in the Open Access Scholarly Publishers Association (OASPA) or the compliance with the OASPA membership criteria. Click and Borchardt (2019) also concluded that many funds require authors to include an acknowledgement statement in their articles.

\section{Conclusions}

The academic/scientific publication in OA is already a current practice, and the tendency is that it will continue to be adopted worldwide by academics and researchers to disseminate the results of their work to the scientific community and the public at large. This widespread use of OA requires a rigorous assessment and understanding of the various funding models and how they support publication in OA across all scientific disciplines and dissemination formats of research results (Copiello, 2020).

According to the various funding models, researchers have academic freedom to choose where and how to publish (Ross-Hellauer et al., 2018; Frantsvåg \& Strømme, 2019). Ross-Hellauer et al. (2018) argue that merging of OA platforms is a positive development in terms of knowledge dissemination, considering their purpose of attracting OA publication, reducing its costs and the administrative complexity that underlies the publication process. Furthermore, it is also an important support to innovative Open Science systems.

For this new way of publishing science to grow in a sustained, impartial and robust way, there is the need (i) to ensure the existence of independent scientific advisory boards; (ii) for freedom to publish within certain limits; (iii) of a sustainability strategy to plan for the platform's operation; (iv) for transparency to public scrutiny; and (v) to abide by the law. We must not forget the vital role of peer-review in this new configuration of academic publication (Eykens et al., 2019).

\section{Acknowledgement}

Funding: University of Azores, Interdisciplinary Centre of Social Sciences CICS.UAc/CICS.NOVA.UAc, UID/SOC/04647/2020, with the financial support of FCT/MEC through national funds and when applicable co-financed by FEDER under the PT2020 Partnership Agreement.

\section{References}

Abbott, A. (2018). Career stage and publication in American academia. Sociologia, Problemas e Práticas, 90. https://doi.org/10.7458/SPP20199014297

Aliukonis, V., Poškutè, M., \& Gefenas, E. (2020). Perish or publish dilemma: Challenges to responsible authorship. Medicina, 56(3), 123. https://doi.org/10.3390/medicina56030123

Balaji, B., \& Dhanamjaya, M. (2019). Preprints in scholarly communication: Re-imagining metrics and infrastructures. Publications, 7(1), 6. https://doi.org/10.3390/publications7010006

Besir Demir, S. (2018). A mixed-methods study of the ex post funding incentive policy for scholarly publications in Turkey. Journal of Scholarly Publishing, 49(4), 453-476. https://doi.org/10.3138/jsp.49.4.05 
Botelho, A., Brasil Jr., A., \& Hoelz, M. (2019). Tão longe, tão perto: Sociologia $\mathcal{E}$ antropologia no limiar de uma década [So far, so close: Sociology E anthropology at the threshold of a decade]. Sociology E Anthropology, 9(3), 717-739. http://dx.doi.org/10.159o/2238-38752019v931

Cantrell, M. H., \& Swanson, J. A. (2020). Funding sources for open access article processing charges in the social sciences, arts, and humanities in the United States. Publications, 8(1), 12. https://doi.org/10.339o/publications8010012

Click, A. B., \& Borchardt, R. (2019). Library supported open access funds: Criteria, impact, and viability. Evidence Based Library and Information Practice, 14(4), 21-37. https://doi.org/10.18438/eblip29623

Copiello, S. (2020). Business as usual with article processing charges in the transition towards OA publishing: A case study based on Elsevier. Publications, 8(1), 3. https://doi.org/10.3390/publications8010003

deBronkart, D. (2019). Open access as a revolution: Knowledge alters power. Journal of Medical Internet Research, 21(12), e16368. https://doi.org/10.2196/16368

Eykens, J., Guns, R., Rahman, A. I. M. J., \& Engels, T. C. E. (2019). Identifying publications in questionable journals in the context of performance-based research funding. PLOS ONE, 14(11), e0224541. https://doi.org/10.1371/journal.pone.0224541

Ferreira, C., \& Serpa, S. (2017). Challenges in the teaching of sociology in higher education. Contributions to a discussion. Societies, 7(4), 30. http://dx.doi.org/10.3390/soc7040030

Frantsvåg, J. E., \& Strømme, T. E. (2019). Few open access journals are compliant with Plan S. Publications, 7(2), 26. https://doi.org/10.3390/publications7020026

Gamsby, P. (2019). The common ground of open access and interdisciplinarity. Publications, 8(1), 1. https://doi.org/10.339o/publications8010001

Hughes, T., Stone, M., Aravopoulou, E., Tiu Wright, L., \& Machtynger, L. (2018). Academic research into marketing: Many publications, but little impact? Cogent Business $\mathcal{E}$ Management, 5(1). https://doi.org/10.1080/23311975.2018.1516108

Kortabarria, L. (2020). A new model for scientific publications: A managing editor's view. The Policy of Cultural Rights: Socio-Legal Perspectives on Cultural Diversity, 10(1), 220-245. https://doi.org/10.35295/osls.iisl/oooooooo-0ooo-1112

Lange, J. (2016). Scholarly management publication and open access funding mandates: A review of publisher policies. Ticker: The Academic Business Librarianship Review, 1(3). http://dx.doi.org/10.3998/ticker.16481003.0001.304

Lemke, S., Mehrazar, M., Mazarakis, A., \& Peters, I. (2019). "When you use social media you are not working": Barriers for the use of metrics in social sciences. Frontiers in Research Metrics and Analytics, 3. https://doi.org/10.3389/frma.2018.00039

Mathies, C., Kivistö, J., \& Birnbaum, M. (2019). Following the money? Performance-based funding and the changing publication patterns of Finnish academics. Higher Education, $79(1), \quad 21-37$. https://doi.org/10.1007/s10734-019-00394-4

Million, A., \& Hudson Vitale, C. (2019). Restructuring and formalizing: Scholarly communication as a sustainable growth opportunity in information agencies? https://doi.org/10.31229/osf.io/ygqv5

Plan S. (2020). Making full and immediate open access a reality. Retrieved from https://www.coalition-s.org/

Rawat, S., \& Meena, S. (2014). Publish or perish: Where are we heading? Journal of Research in Medical Sciences, $19(2), 87-89$.

Ross-Hellauer, T., Schmidt, B., \& Kramer, B. (2018). Are funder open access platforms a good idea? SAGE Open, 8(4), 215824401881671. https://doi.org/10.1177/2158244018816717

Sandu, A. (2012). Postmodern Openings management excellence in academic publishing. Postmodern Openings, 3(1), 7-27. Retrieved from http://postmodernopenings.com/archives/783

Sorooshian, S. (2019). New money-making tactic by predatory publishers. Publications, 8(1), 2. https://doi.org/10.339o/publications8010002

Taylor, M. (2019). Mapping the publishing challenges for an open access university press. Publications, 7(4), 63. https://doi.org/10.3390/publications7040063

Tennant, J. P., Crane, H., Crick, T., Davila, J., Enkhbayar, A., Havemann, J., ... Vanholsbeeck, M. (2019). Ten hot topics around scholarly publishing. Publications, 7(2), 34. https://doi.org/10.339o/publications7020034

van Dijk, H., \& van Zelst, M. (2020). Comfortably numb? Researchers' satisfaction with the publication system and a proposal for radical change. Publications, 8(1), 14. https://doi.org/10.339o/publications8010014 